\title{
Public-private partnerships: approaches to assessing economic effects for stakeholders
}

\author{
Elisaveta Markovskaya ${ }^{1}$, Viktoria Holodkova $^{2}$, Dmitry Radushinsky $^{3,}{ }^{,},{ }$Oksana Feoktistova $^{4}$ \\ and Anzhelika Borisova ${ }^{5}$ \\ ${ }^{1}$ The National Research University Higher School of Economics, ul. Soyuza Pechatnikov, 190121, \\ 16, St. Petersburg, Russia \\ 2 St. Petersburg State University, ul. Chaykovskogo 62, 191104, St. Petersburg, Russia \\ ${ }^{3}$ Institute for Entrepreneurship Problems LLC, 12-th line of Vassylievsky island, 11A, 192241, St. \\ Petersburg, Russia \\ ${ }^{4}$ Moscow State Technical University of Civil Aviation, Kronshtadsky, 22, 125009, Moscow, Russia \\ ${ }^{5}$ Moscow State University of Civil Engineering, Yaroslavskoe shosse, 26, 129337, Moscow, Russia
}

\begin{abstract}
The article is devoted to the development of such a form of state property management as a public-private partnership. Public-private partnership is one of the most widespread format of interaction between the state and business. The article analyzes the legal foundations and trends in the development of this form of interaction. Modern methods for assessing risks, benefits and effects for different stakeholders of projects implemented in the form of PPPs are considered. The authors propose their approach to building a financial model and assessing the effects of PPP projects. Taking into account risks, the fair price of participation in the PPP project for both parties is estimated. The proposed financial model can be used to calculate the concession fee in tariff-regulated projects where the state is supposed to participate, usually with the subsequent transfer of the ownership for the created object to the state. The results of the work can be used by departmental and regional centers of public-private partnerships, by specialists of private investor companies and tariff regulation bodies when formulating the financial and economic justification for publicprivate partnership projects, justifying its preference in comparison with other forms of state budget investments.
\end{abstract}

\section{Introduction}

The combination of the advantages of different forms of ownership and interests of the state and private business in solving economic problems is realized through various models of public-private partnership (PPP). If the state strives to improve the quality and increase the volume of services provided, to rational management of state property, the business expects to participate in PPP gaining profits, incrementing value, raising one's own reputation. Together, the tasks to be addressed include both routine maintenance, provision of the population and business with various infrastructure, and to the perspective development of innovative directions of the economy.

* Corresponding author: D.Radoushinsky@gmail.com 
PPP is studied in detail and multilaterally in Russia and abroad. In a generalizing study, ed. E.R. Yescombe [1] there are studied: the specifics of the application of PPP standards in different countries of the world, the shortcomings of PPPs, the decision-making processes for investing and holding state competitions in PPPs, the practical issues of organizing financing for private companies entering into PPP agreements and other. An empirical analysis of the involvement of small and medium-sized businesses in PPPs and amendments to the concluded contracts was carried out by the authors of the American Planning Association, the World Bank and the EBRD [2, 3, 4].

In works [5-10] such aspects of PPP as prices for services in PPP projects in traditional sectors, the impact of public sector reforms on PPP, budget constraints on PPPs, risk transfer and stakeholder relationships, the influence of trust and established relationships, regulatory regulation of PPP contracts are covered. In [11-13], regional experience was analyzed - assessing the effectiveness of PPPs in the construction of toll roads in the United States, implementing an integrated urban mega-project in the city of New Songdo in South Korea, institutional and strategic barriers to PPP in the Netherlands. In a recent paper [14], Professor of the Harvard University J. Macomber discusses the possibilities of using PPPs in the four types of urban agglomerations allocated by him.

The authors of this work suggest a practical approach to the construction of a financial model when assessing the effectiveness of PPP projects by the plan for the respective dependencies. The article describes the principles of building a financial model, as well as the author's approach to assessing the integrated effect, taking into account the complex structure of the participants in the partnership and assessing economic effects for stakeholders.

\section{Methodological approaches and analysis}

The article analyzes the legal foundations and trends in the development of this form of interaction. Modern methods for assessing risks [8], benefits and effects for different stakeholders of projects implemented in the form of PPPs are considered. The authors propose to consider and evaluate PPP projects in terms of 3 aspects: organizational, methodological and managerial (stakeholder). The organizational aspect is that we evaluate the benefits of the project at different levels of functioning of economic entities participating in the project. The methodological approach is that there are many methods that can be adapted for use in the process of assessing the effectiveness of PPP projects. From the point of view of the theory of project management in projects implemented in the format of public-private partnership, there are several stakeholders: the state, business, society. By stakeholders we mean all individuals and / or legal entities that are directly or indirectly interested in the results of the project.

For each of the stakeholders, we can identify the effects that they can assess in the process of analyzing projects implemented in the format of public-private partnership. By effects we mean quantitative and qualitative project results that can be identified and, as a rule, measured [11].

\subsection{Trends in the development of public-private partnership in Russia}

At the end of the 1st quarter. 2017 «Association PPP Development Center» published the results of their research "Public-Private Partnership in Russia 2016-2017: Current Status and Trends, Regions' Rating." Experts identified the main trends in PPP development in Russia [15].

As of the beginning of 2017, the Russian Federation has passed the stage of deciding on the implementation of 2,446 infrastructure projects that involve private investment on the 
principles of PPP. At the same time, more than 480 projects are in the work of authorities and about 1,000, according to expert estimates, are structured by a private partner for launch using the "private initiative" mechanism. Among the PPP projects that passed the decision-making stage on the implementation of the 17th federal level, 238 of the regional level; 2191 - the municipal level. Note that in a similar study published in the 1st quarter. 2016 reported on 1300 PPP projects, for which a decision was made to implement: 15 projects at the federal level, 191 projects at the regional level, and more than 1100 projects at the municipal level. Thus, the largest growth for 2016, almost $100 \%$, is noted for municipal level projects, while at the regional and federal level the growth in the number of projects implemented is more moderate. With regard to municipal PPP projects, it is noted that for 2017 so far, their implementation has been delivered to a maximum of $15-20$ regions of the Russian Federation, where concession mechanisms are actively used. Thus, with the expansion of the geography of implementation in the coming years, the significant growth in the number of municipal-level PPP projects is likely to continue.

The main form of implementation of projects in the form of public-private partnerships continues to be a concession. 2,200 infrastructure projects (mainly in the municipal sector at the municipal level) are already being implemented and will be implemented in the form of a concession agreement. The term "private partner" has been used more actively since 2016, after the adoption of the law on PPP, mainly in PPP / PPP agreements in the social sphere (health, education). To date, there are 70 such projects, concluded within the framework of regional legislation.

The study notes that a number of projects are being implemented today in other organizational and legal forms close to PPP, for example, such as: a long-term investment agreement and a life-cycle contract concluded within the framework of the 223-FZ; life cycle contract within the framework of $44 \mathrm{FL}$; long-term lease of public property, which implies certain investment obligations of the lessee (the RF Civil Code and 135-FZ).

Most PPP projects are implemented in the following areas: communal and energy infrastructure ( $84 \%$ in terms of the number of projects and $27 \%$ in terms of investments), social infrastructure $(11 \%$ in terms of number of projects and $13.5 \%$ in terms of investments), transport infrastructure $3 \%$ for the number of projects and $56 \%$ for the volume of investments). Projects in the information, communication and other spheres of PPP are $2 \%$ in terms of the number of projects and $3.5 \%$ in terms of investments. In such areas as defense, maintenance of law and order, fundamental science, legislative activity of PPP is not used.

As an important development feature, it should be noted that in 2016 the volume of private investments in Russia in PPP projects has more than tripled (from 408 to 1335 billion rubles), which indicates the high role of the adoption of the PPP Law in 2015 and the amendment of the Law on Concessions in the same year to involve private funds in joint projects. At the same time, the ratio of private investment in PPP projects to nominal GDP in Russia is still 3-6 times lower than in countries such as Brazil, India and Argentina.

\subsection{Russian PPP Law}

On January 1, 2016 in Russia took force Federal Law No. 224-FZ of July 13, 2015, "On Public-Private Partnership, Municipal-Private Partnership in the Russian Federation and Amendments to Certain Legislative Acts of the Russian Federation" (hereinafter - the PPP Law ).

Prior to that, most of Russia's PPP projects were implemented under the Law on Concessions, adopted in 2005, and also on the basis of regional legislation on PPPs (according to data for 2015, 71 laws of the subject of the Russian Federation in the sphere of PPP acted in Russia). Prior to the entry into force of the new Federal Law, PPP was 
implemented only by the types (mechanisms) of BTO, DBTO, etc., in which the infrastructure object should be transferred after creation to a public partner (with the exception of several PPP projects, the implementation of which was based on regional legislation)

The main novelties (changes) in the current practice of implementing PPP projects after the entry into force of the federal PPP Law (since January 1, 2016) were as follows.

1. Opportunity to conclude (structure) those public-private partnership projects, including concessions in which ownership should belong to a private partner, the obligation to transfer the object to a public partner after the expiration of its service life (BOOT and the like), and the ownership right assigned to the private partner (BOO and the like). At the same time, the PPP object may remain in private ownership, provided that the amount of financing for the establishment of the facility by the public partner (state) and the market value of the property transferred to them do not exceed the amount of funding provided by the private partner. In other words, if the state invests more in the project than private partners, then upon termination of the agreement, the transfer of the object to public ownership is mandatory.

2. Definition of the closed list of objects that may be subject to the PPP agreement. In comparison with the Law on Concessions, aircraft, communications and communication lines, land reclamation facilities were added, but at the same time, the objects of the communal sphere of motor roads and others, in respect of which the Law on Concessions operate, were excluded from the list. In both laws there are objects of public health, education, culture and sports, electricity and some others.

In 2018, expect a package of amendments to the federal law on PPP, which would expand the list of facilities for which agreements on PPPs can be concluded, including the inclusion of industrial infrastructure, property for servicing state information systems, rental housing.

3. Unlike the Law on Concessions, only the Russian legal entity can act as a private partner in the PPP Law. The PPP Law, therefore, is focused on private resident partners, while foreign investors are more focused on the Law on Concessions. So the Chinese corporation "SinoGidro" and "Rosavtodor" signed a memorandum of intentions to build a bridge over the Lena River in Yakutsk on the basis of a concession agreement, the preparation of which lasts from 2012.

4. In order to improve the effectiveness of public tasks, a mandatory assessment of the effectiveness of the project (financial effectiveness and socio-economic effect) was introduced to identify the existence of a "comparative advantage" before the project is implemented in alternative partnership forms - under a state and municipal contract (clause 8, art. 3 of the PPP Law). The methodology for assessing efficiency and determining the comparative advantage was approved by Order No. 894 of the Ministry of Economic Development and Trade of the Russian Federation of November 30, 2015. The existence of a "comparative advantage" is a criterion that allows to conclude a contract in the form of a PPP.

5. The procedure for initiating the project by a private partner has been introduced. In international practice, the mechanism of unsolicited proposals is recognized as an alternative way to choose the best private partner (concessionaire), ready to implement the project on the only possible or maximally favorable terms. The state considers the investor's proposal and, in case of a positive decision, concludes an agreement with it without holding a tender or gives the initiator a competitive advantage in the event of a tender.

The mechanism for initiating a project by a private partner in the Russian PPP law does not provide for a private partner either the benefits in the competition for the right to conclude an agreement on PWYP, or reimbursement for the preparation of a project (proposal) in the event of a loss in the competition. 
This novelty was introduced after the "run-in" on the mechanism of a private concession initiative, which was introduced in May 2015 and aroused a certain enthusiasm, despite the fact that the total share of the concluded agreements on the initiative of concessionaires following the results of 2015 amid a large number of proposals (209) was only 9\% (18 signed contracts).

The Law on PPP has expanded the possibilities of using public-private partnerships (PPPs) because of a number of innovations:

- Possibility of pledging the PPP facility for financing the project;

- the non-applicability of the use of model agreements approved by the resolutions of the Government of the Russian Federation;

- expansion of the provisions for the conclusion of direct agreements with financing organizations in comparison with the Law on Concessions. These three innovations significantly increased the attractiveness for banks ("bankability") of PPP projects in Russia;

- creation of authorized bodies in the sphere of PPP;

- a number of others.

The current Russian legislation on PPP is developing in three main areas: the PPP law and the expected amendments to it, concession legislation, regional legislation [16]. Note that today PPP in Russia is not implemented in the form of production sharing agreements (PSAs) that were concluded with foreign extractive companies in the 1990s, on conditions that negatively favored this form.

As part of the further development of concession legislation in 2017, the government plans to approve a list of objects of agricultural infrastructure, in relation to which it is possible to conclude concession agreements, which is intended to stimulate the development of PPP in agriculture.

The Law on Concessions and the PPP Law, partly coinciding with the composition of the objects that may be the subject of the agreement, today, on the whole, divide the entire possible set of PPP objects into two groups that correspond to the preferred forms of the contract. For the most frequently implemented model projects, the Concessions Law is more convenient, and for some non-standard projects, the law on PPPs opens new opportunities.

\subsection{Some aspects of project evaluation implemented in the form of public- private partnerships}

The need to assess the effectiveness of projects implemented by the format of publicprivate partnership, starting from the moment the PPP Law comes into force, is part of the organizational scheme for reviewing and analyzing the project by authorized representatives of government bodies $[9,10,11]$.

We can single out several important aspects of the project evaluation, implemented in the format of public-private partnership, from our point of view.

Organizational aspect. Organizationally, the evaluation process depends on the level at which decisions are taken on the project. For example, the materials of the Public-Private Partnership Development Center contain such an organizational chart of the decision of the Investment Fund of the Russian Federation on PPP projects, which is set forth in Government Resolution No. 134 of March 1, 2008, "On Approving the Rules for the Formation and Use of Budgetary Appropriations of the Investment Fund of the Russian Federation "(with amendments and additions).

Organizational aspects of the decision-making process on investing in PPP projects are fixed in the following normative acts: Resolution of the Government of the Russian Federation No. 590 of 12.08.2008 "On the procedure for inspecting investment projects for 
the effectiveness of using federal budget funds aimed at capital investments" from 13.09.2010 № 716 "On approval of the rules for the formation and implementation of the federal targeted investment program," Decree of the Government of the Russian Federation of 03.08.2011 № 648 "On the selection and coordination of the implementation of priority investment projects of the federal districts and amendments to some acts of the Government of the Russian Federation ", Resolution of the Government of the Russian Federation No. 382 of April 30, 2013" On Conducting a Public Technological and Price Audit of Major Investment Projects with State Participation and on Amending Certain Acts of the Government of the Russian Federation ", RF Government Decree of 05.11. 2013 No. 991 "On the procedure for assessing the appropriateness of financing investment projects at the expense of the National Welfare Fund and (or) retirement savings held in thestate management company, on a returnable basis $[12,13] . "$

Managerial aspect. In terms of the theory of project management in projects implemented in the format of public-private partnership, there are several stakeholders: the state, business, society. By stakeholders we mean individuals and / or legal entities that are directly or indirectly interested in the results of the project.

For each of the stakeholders, we can identify the effects that they can assess in the process of analyzing projects implemented in the format of public-private partnership. By effects we mean quantitative and qualitative project results that can be identified and, as a rule, measured [14].

Below is a description of the possible benefits for society, business and the state.

Table 1. Benefits of public-private partnership for its participants (Source: [17]).

\begin{tabular}{|l|l|}
\hline $\begin{array}{l}\text { Interests of the } \\
\text { parts }\end{array}$ & Benefits \\
\hline Government & $\begin{array}{l}\text { Minimization of capital and operating costs for infrastructure } \\
\text { facilities, redistribution of the burden of risks arising in the process of } \\
\text { operation, expansion of the range of projects implemented } \\
\text { simultaneously, access of the state to competencies, technologies and } \\
\text { business management models, with the subsequent possibility of their } \\
\text { adaptation in state and municipal management. }\end{array}$ \\
\hline Enterprises & $\begin{array}{l}\text { Access to a number of public assets that are traditionally closed or } \\
\text { whose participation in non-state structures is limited; guaranteed and } \\
\text { long-term paid state order for the maintenance and operation of the } \\
\text { object of the partnership agreement; benefits in related areas in the form } \\
\text { of benefits and preferences, including when placing a state / municipal } \\
\text { order outside the framework of the PPP agreement. }\end{array}$ \\
\hline Economy & $\begin{array}{l}\text { Multiple acceleration of growth and modernization of the } \\
\text { infrastructure, synergetic effects from combining financial, real and } \\
\text { social capital of business and the state, improving the quality of products } \\
\text { and services, improving the competitive situation in the market and } \\
\text { liberalizing a range of activities, and reducing the burden on the budget } \\
\text { system. }\end{array}$ \\
\hline
\end{tabular}

Methodical aspect. Methodological bases for the evaluation of projects implemented in the PPP format are set out in several normative acts. The methodological recommendations for assessing the effectiveness of investment projects (approved by the Ministry of Economics of the Russian Federation, the Ministry of Finance of the Russian Federation and Gosstroy of the Russian Federation of June 21, 1999, No. V 477) efficiency of investment projects: effectiveness for project initiators, for shareholders, regional and industrial efficiency, and budgetary efficiency [10]. The recommendations outline approaches to forecasting cash flows and to calculating indicators of economic efficiency of investment projects: net present value, internal rate of return, payback period, return on investment index. For regional investment projects, you can use the Order of the Ministry 
of Regional Development of the Russian Federation of October 30, 2009, No. 493 "On Approving the Methodology for Calculating Indicators and Applying Criteria for the Effectiveness of Regional Investment Projects ...". This methodology recommends not only to calculate economic efficiency indicators, but also to estimate the social effect that is achieved as a result of the implementation of the regional project. So, for example, such indicators can be: a) increase of the level of employment of the population in able-bodied age; b) increase of the level of provision of the population with comfortable housing; c) improvement of the environment;

d) increase of accessibility and quality of services to the population in the sphere of transport, health, education, physical culture and sports, culture, housing and communal services.

\subsection{Estimation of the integral economic effect in case of participation of foreign or international organizations in public-private partnership projects}

This methodology assumes an assessment of the integral effect of involving foreign partners in PPP projects. Initially, the methodology was intended to assess this effect in projects involving the production of innovative products. But, in fact, from the point of view of project management, any project has a unique result, which can have signs of innovation. And, consequently, and to many PPP projects, we can apply the methodology we offer.

To determine the integral economic effect of involving a foreign partner in joint activities to create an innovative product within a PPP, the following basic formula can be used:

$$
\text { Eief }=F R f * k 1 * k 2 * k 3-F R d
$$

Where: FRf (NPVf) - the expected financial result from the implementation of the project to create an innovative product in the PPP with the involvement of this foreign (international) company;

$\mathrm{k} 1$ - coefficient defining the scale of the project in the suggested range [0,8: 1,2]: 0,8 municipal project, the total cost of the project is up to 100 million rubles; 1 - the regional project, the cost is from 100 to 500 million rubles; 1.1 - a regional or interregional project, costing between 500 million and 5 billion rubles; 1,2 - the federal project, the cost of more than 5 billion rubles.

$\mathrm{k} 2$ - coefficient determining the level of business reputation (fame) of this foreign (international) company involved in the implementation of the project to create an innovative product within the PPP framework in the range [15]: 1 - the company is known in its country; 1,5 - the company is the world leader, cooperation with which has the highest reputation effect;

$\mathrm{k} 3$ is the ratio of the share of private capital in the project for the creation of an innovative product within the framework of PPP with the involvement of this foreign (international) company in comparison with the involvement of domestic partners or other foreign (international) companies that participate in the tender, the coefficient is determined by the private respective shares;

FRd (NPVd) is the expected financial result from the implementation of the project to create an innovative product within the framework of PPP with the involvement of a domestic or foreign company that is accepted as the base option

Moreover, formula (1) can take into account other factors, the influence (weight) of which can be determined by the method of expert estimates [18]. 


\subsection{Approaches to building a financial model and assessing the effects of a project implemented in the form of PPPs: Russian practice}

Implementation of the project in the form of public-private partnerships should provide mutual benefits for both sides involved in the transaction, for both the public and the share of the private partner.

On general, the base principle of formation of the remuneration understand at a basic level - for the implementation of the project costs must be offset by income from private business project, as well as getting some profit. This principle is particularly significant for the private partner, as the public partner in projects of public-private partnership performs primarily its social function, which provides taxpayer funds. Therefore, the public partner does not need to extract any financial benefit from the project.

Note that part of the public-private partnership projects at the same time is subject to the necessary and additional state regulation of tariffs. This state regulation (see. Law of the Russian Federation of the PPP Nofar.7) affects the preparation and formation calculations on financial model. If, in accordance with the agreement on public-private partnership provides for the production of goods, works and services carried out at regulated prices/tariffs and (or) based one stablished allowances to the prices/tariffs, procedures and conditions for establishing and changing prices/tariffs on manufactured goods, performed work, rendered services, allowances on prices (tariffs), long-term parameters of regulation of the private partner's activities (see. Law of the Russian Federation of the PPP Nofar.7), subject to approval in accordance and the Russian Federation in the field of price control legislation (tariffs).

Thus, the final version of the financial model for this project of public-private partnership can be formed only after the prices / tariffs on manufactured goods / services will be agreed with the relevant regulatory authorities.

In addition, the agreement on public-private partnership may be a charge made by the private partner public partner during the operation and (or) maintenance of the facility agreement (see. Law of the Russian Federation of the PPP, Ch.9).

The introduction of such a payment may be provided both during the entire life of the service and / or maintenance of the object of the agreement, and during certain periods of its operation and / or maintenance. The amount of such payment, as well as its form, procedure and timing of its introduction are established by the PPP agreement [16].

In the construction of the project's financial model [17] is necessary to make a series of actions that will form a model more accurately and correctly.

The following scheme for constructing a financial model is proposed:

1. Formation of the overall project of PPP model (including various production and basic financial indicators).

2. Construction of the forecasted statements (including balance sheet, profit and loss statement, cash flow statement).

3. Calculation of the pure discounted cash flow.

In building the financial model for this scheme, it is necessary to consider that the amount of state participation in the transaction is determined by the size of the rate of profit and the amount of depreciation in the absence of borrowed funds.

In the presence of debt financing to private investors also offset by interest paid for the use of debt financing.

Thus, in order to determine the amount required to be paid, the project is preparing a financial model of the project of PPP.

Formation of a financial model for the implementation of the public-private partnership project takes place taking into account the use of own and borrowed funds.

As part of the formation of the financial model, the amount to be paid by the private partner from the project to cover its expenses is calculated. 
The amount is calculated for each year of the provision of services / sales of products, on the following conditions:

The expected amount to be received by a private partner for each calendar year for the provision of services / sales of products is calculated by the following formula:

$$
P_{\mathrm{t}}=P\left(I_{\mathrm{t}}\right)+P\left(F C_{\mathrm{t}}\right)+P\left(V C_{\mathrm{t}}\right)
$$

where:

$P_{t}$ - the expected value in year $\mathrm{t}$;

$P\left(I_{t}\right)$ - part of the expected investment in year $t$;

$P\left(F C_{t}\right)$-expected permanentcosts inyear $\mathrm{t}$;

$P\left(V C_{t}\right)$ - expected variable costs in year $t$.

The expected value of the constant operating part in formula (1) for each t year of the provision of services / sales of products is calculated by the following formula:

$$
P\left(F C_{t}\right)=\sum_{j=1}^{n} F C_{t j} \ln d(t)
$$

where:

$F C_{t j}$ - compensation of $\mathrm{j}$-type costs for t-year;

Ind $(t)$ - the forecasted index in $t$ year.

The expected value of the operating variable part in formula (1) for each t service year is calculated using the following formula:

$$
P\left(V C_{t}\right)=\sum_{i=1}^{n} V_{t}(i) \sum_{j=1}^{m} V C_{t j} \ln d_{j}(t)
$$

where:

$V_{t}(i)$ - expected volume ofthe i-th type of services / goods inyear $t$;

$V C_{t j}$ - compensation costs in theform ofj-thforyear t;

$\ln d_{j}(t)$ - forecast the indexj-th species inyear t.

When building a financial model of public-private partnerships must take into account that the magnitude of the sum necessary for the private partners for the project should be not less than the sum (formula 1).

Thus, if we calculate the financial model of a project implemented through a publicprivate partnership scheme (a simplified example of such a calculation is given below, see Table 2.), the amounts of subsidies received should be calculated taking into account the constraints obtained by formulas (1) - (3).

Table 2. Simplified financial model for calculating the subsidy for falling costs by the publicprivate partnership model.

\begin{tabular}{|c|c|c|c|c|c|}
\hline Indicator name & Units & 2017 & 2018 & 2019 & 2020 \\
\hline $\begin{array}{c}\text { Income from goods } \\
\text { services }\end{array}$ & rub. & 54872 & 58620 & 61025 & 64230 \\
\hline $\begin{array}{c}\text { Income from non- } \\
\text { core activities }\end{array}$ & rub. & 4510 & 4826 & 5163 & 5525 \\
\hline Total revenues & rub. & 59382 & 63446 & 66188 & 69755 \\
\hline $\begin{array}{c}\text { Cost of sales of } \\
\text { goods / services }\end{array}$ & rub. & 32923 & 35172 & 36615 & 38538 \\
\hline Production costs & rub. & 5487 & 5862 & 6103 & 6423 \\
\hline Depreciation & rub. & 20500 & 20500 & 20500 & 20500 \\
\hline Property tax & rub. & 560 & 560 & 560 & 560 \\
\hline $\begin{array}{c}\text { Expenditures for } \\
\text { social development and } \\
\text { other purposes }\end{array}$ & rub. & 1540 & 1540 & 1540 & 1540 \\
\hline
\end{tabular}




\begin{tabular}{|c|l|l|l|l|l|}
\hline Indicator name & Units & 2017 & 2018 & 2019 & 2020 \\
\hline $\begin{array}{c}\text { Project management } \\
\text { costs }\end{array}$ & rub. & 420 & 420 & 420 & 420 \\
\hline Interest on loans & rub. & 890 & 890 & 890 & 890 \\
\hline Total costs & rub. & 62320 & 64944 & 66628 & 68871 \\
\hline Drop-out costs & rub. & 2938 & 1498 & 439 & -884 \\
\hline $\begin{array}{c}\text { Subsidies from the } \\
\text { budget }\end{array}$ & rub. & 2938 & 1498 & 439 & -884 \\
\hline
\end{tabular}

In addition, in the implementation stage of the project in the formula may also take into account the income of the investor from the project, that is part of the amount $\mathrm{P}_{\mathrm{t}}$ at the stage of operation of the project can be covered through income from the project itself $[17,18]$.

Most of the projects implemented in the format of public-private partnerships imply a gradual coverage of the investor's expenses for the project implementation at the expense of revenues received from its implementation.

However, it is also necessary to take into account that the investor pays attention not only to the gross income, but also on the distribution of funds in time.

In conclusion, it should be noted that any project of public-private partnerships involve an interest in the project, as a private investor in the form of financial benefits, as well as from the state party in the form of implementation necessary for the tasks of the state, to ensure public infrastructure, social facilities and other tasks, which are traditionally resolved at the state level $[19,20]$.

\section{Results}

In the descriptive part the issue analyses the trends in the development of public-private partnership in Russia, the new possibilities as well as constraints of a Russian PPP Law which works since 2016. While considering the aspects of project evaluation implemented in the form of PPP the authors seek an approach to the construction of a financial model when assessing the effectiveness of PPP projects by the plan for the respective dependencies. The principles of building a financial model are described which take into consideration the modern methods for assessing risks, benefits and effects for different stakeholders of projects implemented in the form of PPPs. In the final part the article describes an approach for assessing the integrated effect, taking into account the complex structure of the participants in the partnership and assessment of economic effects for stakeholders.

\section{Conclusion}

We examined approaches that can be used by stakeholders in the process of assessing the risks and effects of public-private partnership projects. Taking into account risks, the fair price of participation in the PPP project for both parties is estimated. The proposed financial model can be used to calculate the concession fee in tariff-regulated projects where the state is supposed to participate, usually with the subsequent transfer of the ownership for the created object to the state.

The results of the work can be used by departmental and regional centers of publicprivate partnerships, by specialists of private investor companies and tariff regulation bodies when formulating the financial and economic justification for public-private partnership projects, justifying its preference in comparison with other forms of state budget investments. 
Further areas of research may be the following: developing a methodology for assessing the risks and effects of public-private partnership projects taking into account the industry specificity.

\section{References}

1. A. Polyakova, E. Vasilyeva, Procedia engineering 165, 1380-1387

2. L.B. Sagalyn, Journal of the American Planning Association 73(1), 7-22 (2007)

3. A. Mottaeva, MATEC Web of Conferences 106, 08071 (2017)

4. A. Mottaeva, MATEC Web of Conferences 106, 08072 (2017)

5. I. Polyakova, E. Chibisova, Economy and entrepreneurship 5(70), 579-582 (2016)

6. I. Polyakova, E. Vasilyeva, Economy and entrepreneurship 4-2(81-2), 1024-1028 (2017)

7. D. Makovšek, Journal of Transport Economics and Policy (JTEP) 47(1), 143-155 (2013)

8. E. Caperchione, I. Demirag, G. Grossi, Accounting Forum 41-1, 1-7 (2017)

9. M. Buso, F. Marty, P. TraTran, International Journal of Industrial Organization 51, 5684 (2017)

10. R.Burke, I.Demirag, Accounting Forum 41(1), 28-43 (2017)

11. C. Benítez-Ávila, International Journal of Project Management 36(3), 429-443 (2018)

12. G. Diaz, Utilities Policy 48, 109-121 (2017)

13. J. Kweun, P. Wheeler, J. L. Gifford, Transport Policy 62, 12-20 (2018)

14. Yoon-jung Kim, Cities 72A, 43-50 (2018)

15. A. Klijn, G. Teisman, Public Money and Management 2(3), 137-146 (2003)

16. A. Mottaeva, IOP Conference Series: Earth and Environmental Science 90(1), 012124 (2017)

17. A. Mottaeva, MATEC Web of Conferences 106, 08071 (2017)

18. A. Mottaeva, MATEC Web of Conferences 106, 08072 (2017)

19. V. Kolmakov, Modern scientific research and innovation 9-53, 196 (2015)

20. A. Radoushinsky, Scientific and technical lists of the St. Petersburg State Polytechnic University. Economic sciences 5(251), 57-71 (2016) 